\title{
Combination Macrophage-Colony Stimulating Factor and Interferon- $\gamma$ Administration Ameliorates the Osteopetrotic Condition in Microphthalmic (mi/mi) Mice
}

\author{
RAMONA MARIE RODRIGUIZ, L. LYNDON KEY, JR, AND WILLIAM L. RIES \\ Division of Endocrinology, Department of Pediatrics, Medical University of South Carolina, Charleston. \\ South Carolina 29425
}

\begin{abstract}
Malignant osteopetrosis is a fatal congenital bone disorder characterized by defective osteoclastic function. Death frequently occurs within the first decade of life. The precise molecular defect(s) that causes osteopetrosis is not known. The possibility that osteoclasts, like macrophages, are controlled by interactions with cytokines suggests that these agents may provide a means of increasing osteoclastic function. Macrophage-colony stimulating factor (M-CSF), a cytokine known to enhance macrophage and osteoclast generation, and recombinant human interferon- $\gamma$ (rIFN), a cytokine known to stimulate superoxide generation by white cells, were administered to microphthalmic $(\mathrm{mi} / \mathrm{mi})$ mice in an attempt to improve the osteopetrotic condition. Each cytokine was administered separately and in combination to neonatal $\mathrm{mi} / \mathrm{mi}$ mice for 7 consecutive d. Bone turnover, osteoclast numbers, superoxide generation by white cells, and hematocrit were assessed. rIFN, M-CSF, and a combination of the cytokines stimulates oxygen-derived free radical production by white cells and increased bone resorption. rIFN resulted in a reduction in the number of osteoclasts. This reduction in number was ameliorated by M-CSF. M-CSF alone and in combination with rIFN resulted in improved hematopoietic function, increased weight gain, and increased physical activity of the affected mutants. (Pediatr Res 33: 384-389, 1993)
\end{abstract}

\section{Abbreviations}

rIFN, recombinant interferon- $\gamma$

M-CSF, macrophage-colony stimulating factor $\mathrm{mi} / \mathrm{mi}$, microphthalmic mutant $\mathrm{C} 57 \mathrm{B1} / 6$ mouse $+/ \mathrm{mi}$, heterozygote microphthalmic C57B1/6 mouse $+/+$, normal C57B1/6 mouse

NBT, nitroblue tetrazolium

Severe, congenital osteopetrosis is a fatal disorder that is characterized by the inability of the osteoclast to resorb bone. Due to inadequate bone remodeling, medullary cavities are severely restricted, leading to dense, sclerotic bone. These bones are structurally weakened and thickened. This weakness results in

Received January 14, 1992; accepted December 9, 1992

Correspondence and reprint requests: L. Lyndon Key, Jr. M.D. Division of Pediatric Endocrinology, Medical University of South Carolina, 171 Ashley Ave., Charleston, SC 29425

Supported by March of Dimes No. 6-575 and the Children's Hospital Fund of the Medical University of South Carolina, Charleston, SC, and the Brenner Children's Hospital of North Carolina Baptist Hospital, Winston Salem, NC. an increased fracture frequency. The thickness leads to encroachment of the normal marrow space and resultant pancytopenia, as well as cranial nerve compression due to a reduction in the diameter of cranial foramina (1).

Several defects have been identified that may help to elucidate the abnormal osteoclastic function resulting in this sclerosing bony dysplasia. First, a defect in white cell and osteoclastic superoxide generation has been identified in both animals and humans $(2,3)$. Second, a defect in the M-CSF gene, resulting in no measurable M-CSF activity and a reduced or absent population of osteoclasts, has been documented in the osteopetrotic (op/op) mouse $(4,5)$.

Superoxide generation has been shown to be associated with bone resorption $(1,6)$. Thus, a defect in superoxide production by osteoclasts would be expected to reduce their function. Defective superoxide production by the white cells of patients with chronic granulomatous disease has been restored using rIFN therapy (7). In addition, the production of oxygen-derived free radicals has been located within the ruffled border areas of active osteoclasts (3). These findings suggest that rIFN might help to reverse the osteopetrotic defect through the stimulation of superoxide production.

The op/op mouse has a defect in the production of mature functional macrophages and osteoclasts (8). Normal numbers of osteoclasts and macrophages with resultant normalization of bone resorption have been seen after treatment with M-CSF ( 9 . 10). It has been demonstrated that M-CSF in the in vitro hematopoietic colonies of op/op mice is necessary for the restoration of osteoclast formation (11). In contrast to the animal model, a defect in M-CSF production and function is not expected in the majority of patients with congenital malignant osteopetrosis, because in general there has not been a reduced number of macrophages or osteoclasts. Indeed, Orchard et al. (12) have demonstrated normal circulating levels of biologically active MCSF in patients with severe congenital osteopetrosis. The possibility that there could be an M-CSF receptor defect that could be treated with high doses of M-CSF has not been explored. Thus, there is the possibility that pharmacologic doses could result in improved bone resorption in nondeficient animals.

The $\mathrm{mi} / \mathrm{mi}$ mouse has been used as a model of human congenital osteopetrosis $(13,14)$. These mice have normal numbers of macrophages and osteoclasts (7). The osteoclasts and the white cells have defective superoxide production (1). Thus, this model serves as an excellent system to test the effects of rIFN and MCSF on bone resorption in an animal model system that appears to resemble the human phenotype.

\section{MATERIALS AND METHODS}

Materials. Microphthalmic mice were obtained by breeding heterozygotes $(+/ \mathrm{mi}, \mathrm{C} 57 \mathrm{~B} 1 / 6$, Midwestern Biomedical, Dr. 
A

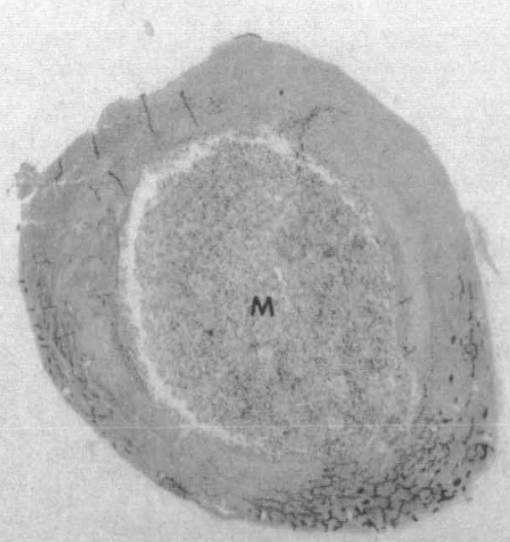

B

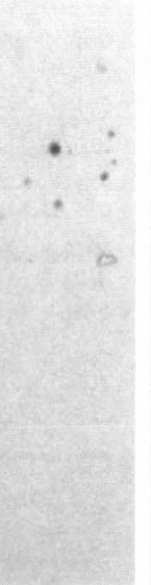

D
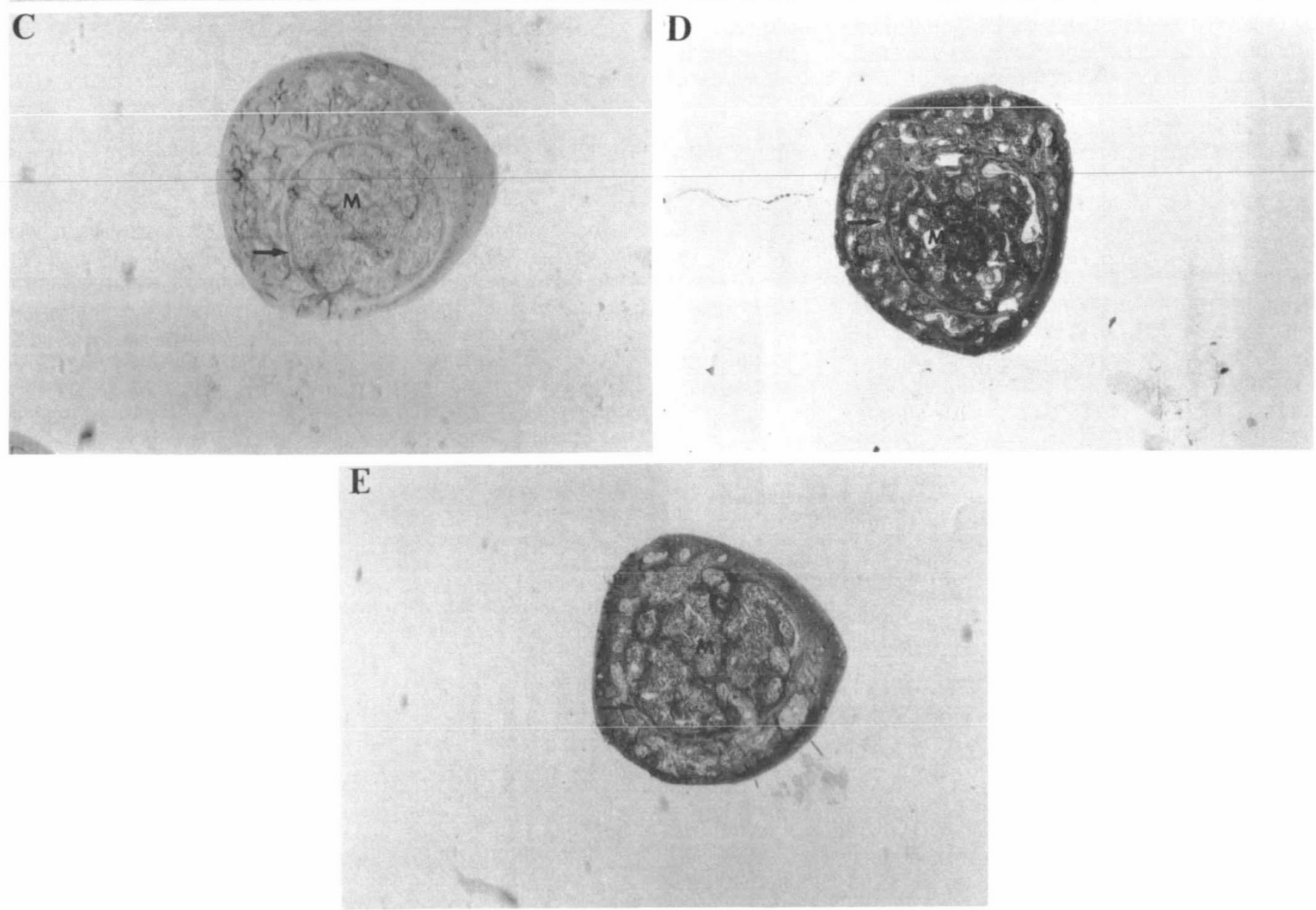

Fig. 1. Cross-sections of tibial mid-diaphyses from control and experimental mi/mi mice after $7 \mathrm{~d}$ of treatment. $A$, Control tibia from pups $(+/$ $\mathrm{mi}$ ) receiving saline. Note the dense compact bone surrounding a large marrow cavity $(M)$. $B$, Section of tibia from saline-treated mutant (mi/mi). The cortical bone surrounding a relatively small marrow cavity $(M)$ is highly porous, except for a dense outer compact bone rim and a thin inner compact bone rim (arrow) surrounding the marrow cavity. $C$, rIFN-treated mutant. Note the increase in the size of the marrow cavity ( $M$ ) surrounded by the inner compact bone rim (arrow) and the increased cellularity within the enlarged marrow space. The cortical bone surrounding the marrow cavity shows increased porosity. D. M-CSF-treated mutant. Note similar changes in tibial morphology of this specimen as described for panel C. E. Combination rIFN and M-CSF treatment. In this specimen, most of the inner compact bone rim (arrow) surrounding the enlarged marrow cavity $(M)$ has been eroded, and is now continuous with a porous cortical bone that structurally resembles trabecular bone. $A-E$, original magnification $\times 400$.

Robert Jilka). The neonatal mutant mice were easily recognized at birth by lack of tissue maturation in the orbital area. All mice $(\mathrm{mi} / \mathrm{mi},+/ \mathrm{mi}$, and $+/+)$ were kept with their natural mothers and allowed unrestricted access to them throughout the course of the experiment. The animal experimentation was performed with the highest standards of humane care and was approved by the animal resources committees of the Bowman Gray School of

Medicine, Wake Forest University, Winston-Salem, NC, and the Medical University of South Carolina at Charleston.

Recombinant human M-CSF (generously provided by Genetics Institute, Cambridge, MA) upon reconstitution yielded a concentration of $2 \mathrm{mg} / \mathrm{mL}$ in buffer of $0.5 \mathrm{M}$ glycine, $10 \mathrm{mM}$ sodium citrate, $1 \%$ sucrose, and $0.05 \%$ Tween 80 at a pH of 6.0 . rIFN was obtained from Genentech Incorporated (S. San Fran- 
Table 1. Effects of rIFN, M-CSF, or combined cytokine treatment on hematologic parameters of normal and osteopetrotic mi/mi mice after 7 consecutive $d$ of treatment*

NBT-stained hematopoietic colonies (OD units)

\begin{tabular}{|c|c|c|c|c|c|}
\hline \multirow[b]{2}{*}{ Group } & \multirow[b]{2}{*}{$n$} & \multirow[b]{2}{*}{ Hematocrit } & \multirow[b]{2}{*}{$\%$ Marrow } & \multicolumn{2}{|c|}{$\begin{array}{l}\text { NBT-stained hematopoietic colonies } \\
\text { (OD units) }\end{array}$} \\
\hline & & & & $\begin{array}{l}\text { Without } \\
\text { rIFN }\end{array}$ & With rIFN \\
\hline \multicolumn{6}{|c|}{ Osteopetrotic ( $\mathrm{mi} / \mathrm{mi})$} \\
\hline Saline & 15 & $37.71 \pm 15.0 \dagger$ & $7.96 \pm 5.7$ & $0.215 \pm 0.1$ & $0.436 \pm 0.1 \ddagger$ \\
\hline rIFN & 16 & $37.42 \pm 10.1 \dagger$ & $40.70 \pm 12.7 \S$ & $0.687 \pm 0.1$ & $0.737 \pm 0.1 \ddagger$ \\
\hline \multicolumn{6}{|c|}{ Normal $(\mathrm{mi} /+$ or $+/+)$} \\
\hline Saline $\|$ & 6 & $45.10 \pm 3.3$ & $42.42 \pm 2.9$ & $0.273 \pm 0.0$ & $0.336 \pm 0.19$ \\
\hline rIFN\| & 6 & $44.90 \pm 3.6$ & $43.42 \pm 5.5$ & $0.218 \pm 0.1$ & $0.319 \pm 0.19$ \\
\hline
\end{tabular}

$*$ Values are expressed as mean \pm SEM

$\dagger p<0.05$ (compared with normal animals).

$\ddagger p<0.02$ (compared with colonies without rIFN).

$\S p<0.001$ (compared with $\mathrm{mi} / \mathrm{mi}$ saline).

$\|$ No significant differences were found between saline- and rIFN-treated normal animals.

I $p<0.008$ (compared with colonies without rIFN).

Table 2. Effects of rIFN, M-CSF, or combined cytokine therapy on total number of osteoclasts in osteopetrotic mi/mi mice after 7 consecutive $d$ of treatment ${ }^{*}$

\begin{tabular}{cc}
\hline \multicolumn{1}{c}{ Condition } & $\begin{array}{c}\text { Total no. osteoclasts } \\
\left(/ 1600 \mu \mathrm{g}^{2} \text { marrow }\right)\end{array}$ \\
\hline Osteopetrotic $(\mathrm{mi} / \mathrm{mi})$ & \\
Saline & $11.00 \pm 1.23$ \\
rIFN & $7.80 \pm 0.72 \dagger$ \\
M-CSF & $9.10 \pm 0.61 \ddagger$ \\
rIFN $+\mathrm{M}-\mathrm{CSF}$ & $12.20 \pm 1.12 \ddagger$ \\
Normal $(\mathrm{mi} /+$ or $+/+)$ & \\
Saline & $5.30 \pm 0.44$ \\
rIFN & $4.00 \pm 0.24 \dagger$ \\
\hline
\end{tabular}

* Values are expressed as mean \pm SEM.

$\dagger p<0.03$; a significant decrease when compared with saline-injected animals.

$\ddagger p<0.004$; a significant increase when compared with rIFN-injected animals

cisco, CA), supplied in injectable form at $0.2 \mathrm{mg} / \mathrm{mL}$ concentration. At 12 to $16 \mathrm{~d}$ of age, $\mathrm{mi} / \mathrm{mi}$ mice were randomly assigned to one of four treatment groups: rIFN, $1.5 \mu \mathrm{g} / \mathrm{kg} / \mathrm{d} ; \mathrm{M}-\mathrm{CSF}, 500$ $\mu \mathrm{g} / \mathrm{kg} / \mathrm{d}$; a combination of both cytokines; and sham treatment of $0.05 \mathrm{~mL} / \mathrm{d}$ of vehicle $(0.9 \% \mathrm{NaCl})$. Nonmutant mice were randomly assigned to either one of two treatment conditions: $\operatorname{rIFN}(1.5 \mu \mathrm{g} / \mathrm{kg} / \mathrm{d})$ or a sham treatment of $0.05 \mathrm{~mL} / \mathrm{d}$ of vehicle. All test agents were administered once daily by an s.c. injection.

Hematologic measurements. After 7 consecutive d of treatment, the mice were weighed and killed with a lethal intraperitoneal injection of sodium pentobarbital $(100 \mathrm{mg} / \mathrm{kg})$. Blood was drawn $(50 \mu \mathrm{L})$ by cardiac puncture and used to determine the hematocrit. The spleen of each animal was dissected free and placed into separate, sterile, $32-\mathrm{mm}$ plastic Petri dishes containing PBS, $\mathrm{pH}$ 7.3. The spleens were minced, and the tissue debris was separated by filtering over sterile gauze into $13-\mathrm{mL}$ plastic centrifuge tubes. The cellular suspension was centrifuged at 1200 $\times g$ for $15 \mathrm{~min}$ at room temperature. The supernatant was discarded, and the pellet was resuspended in $2.2 \mathrm{~mL}$ of sterile agar-based BGJ media (Sigma, St. Louis, MO) with $10.0 \%$ FCS (Sigma), $1 \%$ penicillin-streptomycin solution (Sigma), and supplemented with $10 \mathrm{ng} / \mathrm{mL}$ of CSF-1 (Genzyme, Cambridge, MA). One mL of the suspension was piated into each of two 16 mm wells (24-well plates, Corning, Corning, NY). Only one of these wells contained $40 \mu \mathrm{g}$ rIFN; the other well served as a control. The cells were incubated at $37^{\circ} \mathrm{C}$, in $5.0 \% \mathrm{CO}_{2}$ and air for $7 \mathrm{~d}$.
After incubation, $550 \mu \mathrm{L}$ of a filtered NBT solution $[5.0 \mathrm{mg}$ NBT (Sigma), $60 \mu$ L DMSO (Sigma), 1.6 mL FCS, 2.9 mL BJG (Sigma), pH 7.3] was added to each well and incubated for 30 min at $37^{\circ} \mathrm{C}$. NBT staining intensity of 20 hematopoietic colonies per well was assessed (OD units) using a densitometry analysis system (Cue 2, Opelco, Washington DC).

Histomorphometry. The tibias of each animal were dissected free of soft tissue, sectioned in half at the mid-diaphysis, and fixed in $2.5 \%$ glutaraldehyde in $0.1 \mathrm{M}$ cacodylate buffer. The specimens were decalcified in 5\% EDTA, dehydrated in increasing concentrations of ethanol, and embedded in Spurr's resin (Polysciences, Warrington, PA). Serial cross-sections ( 1 to $2 \mu \mathrm{m}$ ) of the mid-diaphysis were stained with toluidine blue $(1 \%$ aqueous solution) and analyzed histomorphometrically using an Olympus inverted microscope and a digital analysis (Cue 3, Opelco). The percentage of the bone marrow space relative to the total bone area was measured. Marrow cellularity was measured by determining the number of nuclei within a given marrow space area $\left(100 \mu \mathrm{m}^{2}\right)$. Total osteoclast number was assessed within a standardized area of $1600 \mu \mathrm{m}^{2}$ of marrow space at $2500 \times$.

Statistical analysis. All data have been expressed as mean \pm SEM. Differences between experimental and control groups were analyzed for significance using the $t$ test. Relationships between variables were measured using the Pearson product-moment correlation coefficient $\left(r_{\mathrm{p}}\right)$.

\section{RESULTS}

The $\mathrm{mi} / \mathrm{mi}$ mice treated with either rIFN, M-CSF, or a combination of the two cytokines demonstrated a significant increase in the percentage of the bone cross-sectional area containing marrow elements (Fig. 1) compared with that of sham-treated $\mathrm{mi} / \mathrm{mi}$ mice (Table $1, p<0.001$ ).

Microphthalmic mice were noted to have $48 \%$ more osteoclasts than their normal littermates $(p<0.0001)$. During therapy, the total osteoclast number was significantly decreased in $\mathrm{mi} / \mathrm{mi}$ mice that received rIFN (Table 2, $p<0.03$ ). Mutant animals that received M-CSF, either alone or in combination with rIFN, demonstrated no significant change in total osteoclast number when compared with saline-treated mutants but did show a significant increase compared with rIFN-treated mutant animals (Table 2, $p<0.004$ ).

The bone sections (Fig. 2) from $\mathrm{mi} / \mathrm{mi}$ mice treated with rIFN, M-CSF, or a combination of the cytokines demonstrated a greater marrow cellularity (expressed as cells per cross-section and cells per $100 \mu \mathrm{m}^{2}$ ) than the saline-treated mutants (Table 3 , 


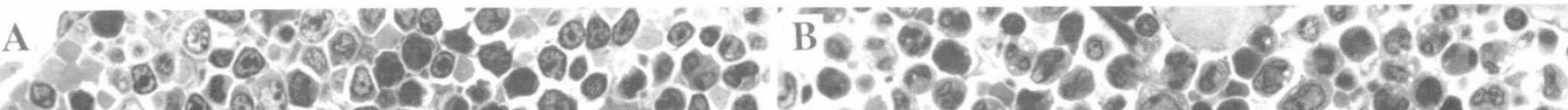

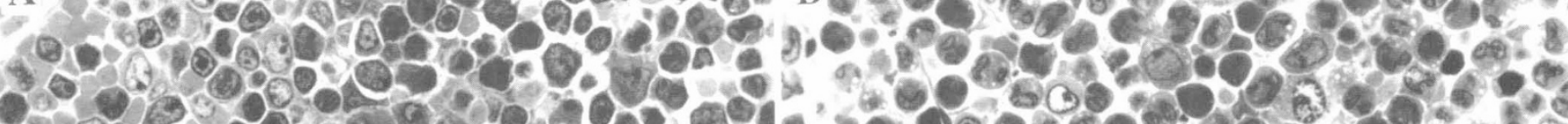

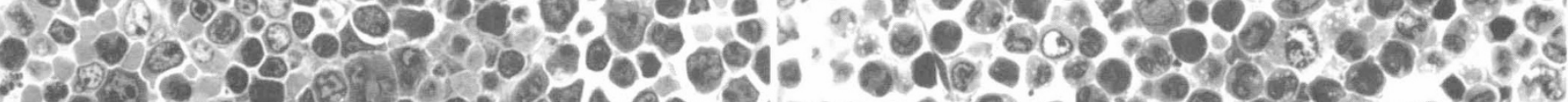

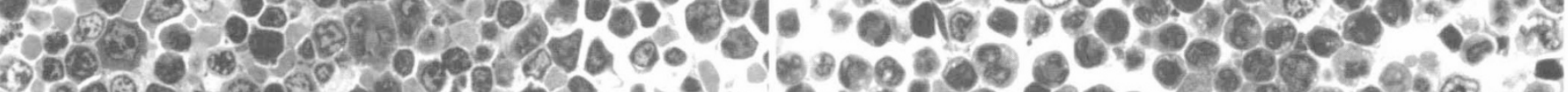
10.0.

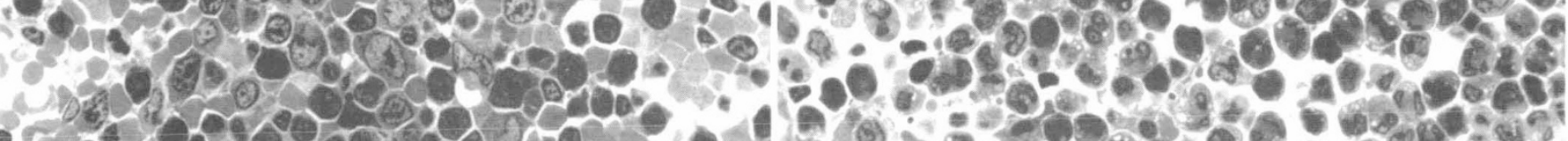

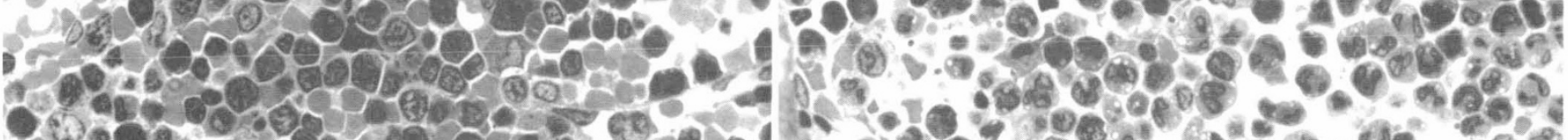

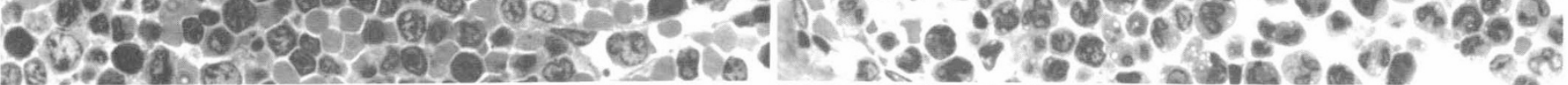

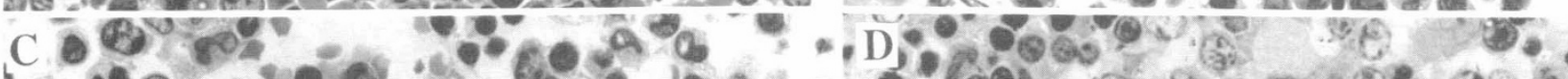

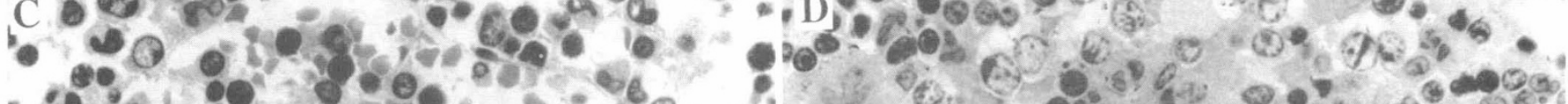

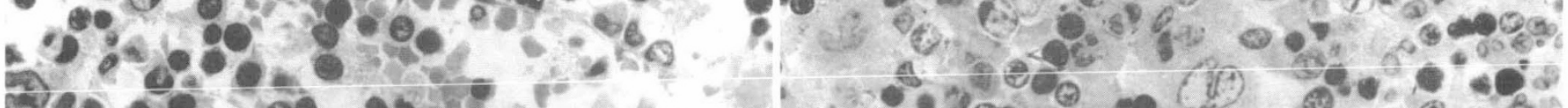

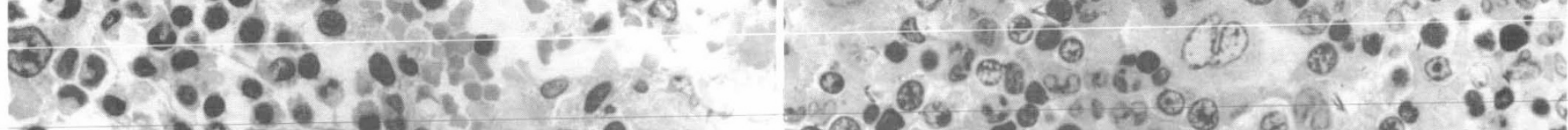

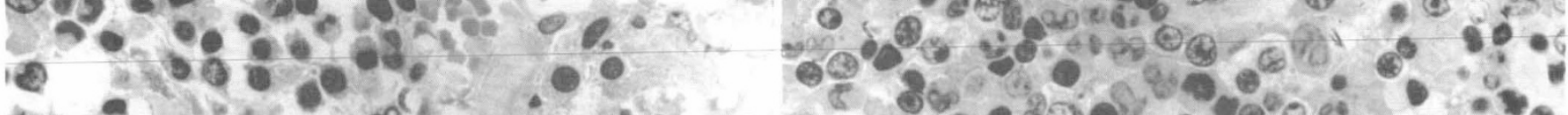

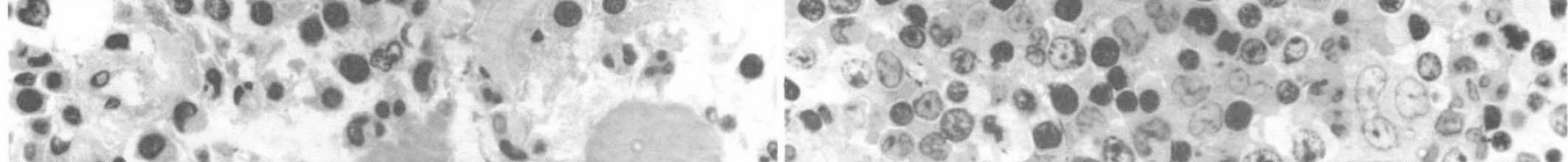

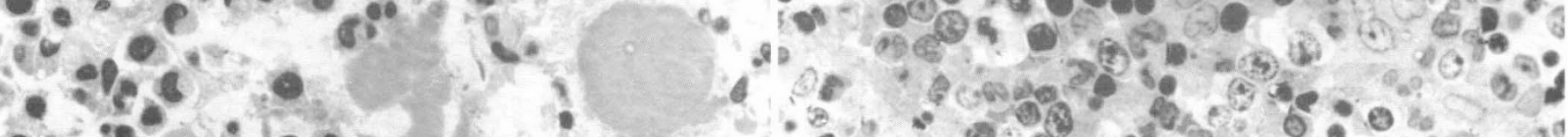
- * - . - . iE w -

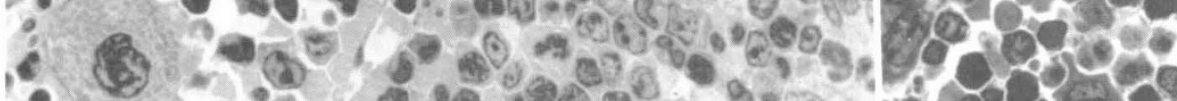

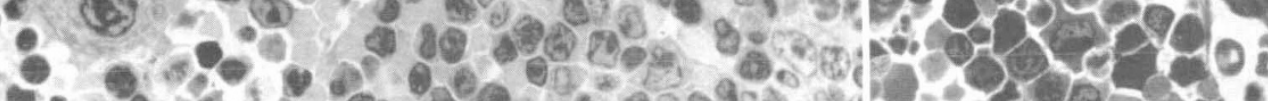

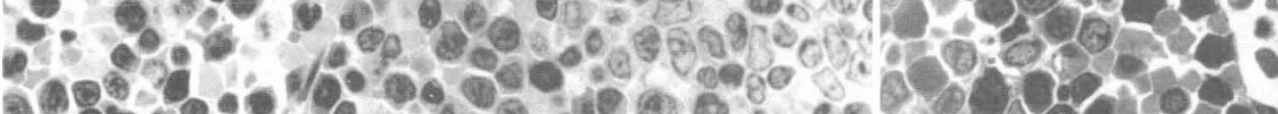
\% है।

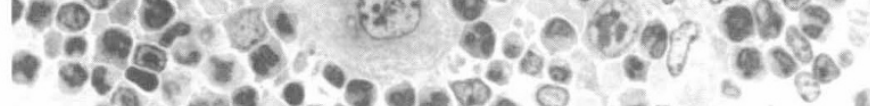

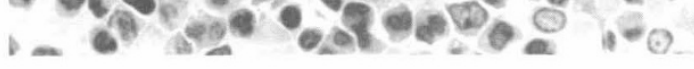
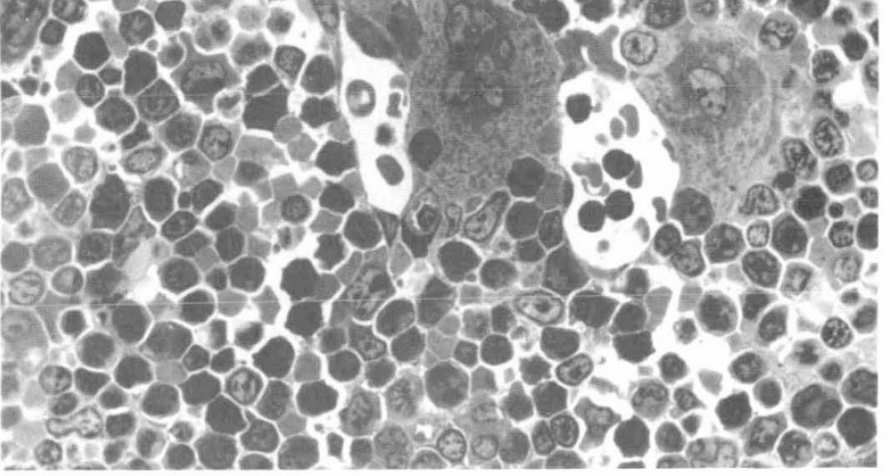

Fig, 2. Cross-sections of marrow cavities depicting cell

riginal magnification $\times 1000$

cellular

There is a positive correlation between the marrow

saline and with rIFN were significantly lower than those of the normal animals (Table $3 . p<0.05$ ). Conversely, the mean
hematocrits of animals treated with $\mathrm{M}$-CSF alone or in combiThe OD of the NBT-stained hematopoietic colonies was given saline (Table $1, p<0.001$ ). Cultured hematopoietic colonies from the spleens of $\mathrm{mi} / \mathrm{mi}$ responded to rIFN with a signifgreater in colonies from $\mathrm{mi} / \mathrm{mi}$ mice treated with rifN, M-CSF. ment in vivo (Table 1, $p<0.02$ ). The colonies grown from spleen cells of normal mice showed no significant increase in NBT demonstrate an increase when treated in vitro (Table $1, p<$ The weights of the $\mathrm{mi} / \mathrm{mi}$ mice at the start of the experiment 
Table 3. Effects of rIFN, M-CSF, or combined cytokine therapy on bone marrow space cellularity of osteopetrotic mi/mi mice after 7 consecutive $d$ of treatment*

\begin{tabular}{lll}
\hline \multicolumn{1}{c}{ Group } & Cells $/ 100 \mu \mathrm{m}^{2}$ & Total no. cells ${ }^{\dagger}$ \\
\hline Saline & $1.305 \pm 0.32$ & $141.56 \pm 18.06$ \\
rIFN & $2.250 \pm 0.61 \ddagger$ & $424.80 \pm 80.80 \S$ \\
M-CSF & $3.405 \pm 1.20 \|$ & $503.00 \pm 76.85 \S$ \\
rIFN + M-CSF & $4.359 \pm 1.38$ & $714.67 \pm 46.08 \S$ \\
\hline
\end{tabular}

*Values are expressed as mean \pm SEM.

$\dagger$ Total number of countable cells within total marrow area.

$\ddagger p<0.04$ (compared with $\mathrm{mi} / \mathrm{mi}$ saline).

$\S p<0.0008$ (compared with $\mathrm{mi} / \mathrm{mi}$ saline).

$\| p<0.001$ (compared with $\mathrm{mi} / \mathrm{mi}$ saline).

I $p<0.004$ (compared with $\mathrm{mi} / \mathrm{mi}$ saline).

demonstrated a wide variability (data not shown). Therefore, a significant increase or decrease in weight gain after cytokine treatment when compared with the control mutants could not be ascertained. However, the $\mathrm{mi} / \mathrm{mi}$ mice treated with $\mathrm{rIFN}$ alone decreased their weight by $0.42 \pm 0.375 \mathrm{~g}( \pm \mathrm{SEM}, n=16)$. The mutants receiving rIFN in combination with M-CSF increased their weight by $1.38 \pm 0.375 \mathrm{~g}( \pm$ SEM, $n=16)$. This weight increase represented a significant difference when compared with the rIFN-treated group that lost weigth $(p<0.002)$.

\section{DISCUSSION}

The hallmark of osteopetrosis is defective bone resorption resulting from an inadequacy of osteoclastic number or function. Reversal of the osteopetrotic condition depends upon improving bone resorption. After $7 \mathrm{~d}$ of treatment, all cytokine-treated animals demonstrated a significant increase in the amount of bone marrow space. This suggested that net bone resorption (the amount of bone resorption relative to formation) had improved. The improvement in bone resorption dynamics occurred in all treatment groups. In normal animals, there was no change in the percentage of the bone cross-section occupied by bone marrow during rIFN administration. This is not surprising, because the marrow space extends to the outer, single rim of dense cortical bone.

The administration of rIFN to either osteopetrotic mice or their normal littermates did result in a decrease in total osteoclast number. However, it was also demonstrated that in rIFN-treated animals the overall level of bone resorption, as indicated by an increase in marrow space, improved. M-CSF in combination with rIFN restored the total osteoclast number to the level seen in sham-treated animals. The combination therapy was superior to all other therapies, improving the osteopetrotic condition.

Ideally, an increase in marrow space and bone turnover should translate into an improvement of hematopoietic function. The hematocrits measured in the M-CSF-treated animals were not significantly different from those in normal control animals. In addition, there was a significant increase in marrow cellularity in the animals treated with rIFN, M-CSF, or a combination of both cytokines in comparison to controls. As the marrow spaces increased, the number of bone marrow elements within them increased in parallel, suggesting that hematopoiesis was increased along with the intramedullary volume. Longer treatment may result in more demonstrable changes in the peripheral blood.

The hematopoietic colonies grown from the dispersed spleen cells demonstrated a significant increase in NBT reduction in all cytokine-treatment groups. The greatest increase was seen in colonies grown from mutants treated with a combination of rIFN and M-CSF. However, the increased NBT reduction by spleen cell colonies cultured from the mutants treated with $\mathrm{M}$ CSF alone would suggest that not only rIFN but also M-CSF enhances superoxide production. Normal mice receiving rIFN in vivo had no significant increase in NBT reduction. However, the white cells from the hematopoietic colonies of both the normal and $\mathrm{mi} / \mathrm{mi}$ mice demonstrated a significant increase when cultured with rIFN in vitro.

Death in patients with osteopetrosis frequently occurs secondary to infection, long before neutropenia is present (2). Thus, the increase in superoxide generation seen in the white cells of all M-CSF and rIFN treatment groups may prove important. The marked increase in the oxygen radical formation of white cell colonies demonstrated in the present study may provide preclinical data, paving the way for trials of rIFN and M-CSF among osteopetrotic patients, in attempts to reduce death due to infection.

Weight gain was used to assess the overall health of the animals. When compared with the saline-treated controls, only the groups of animals receiving either M-CSF or a combination of cytokines demonstrated a significant increase in net weight gain. Mutant animals treated with rIFN lost weight, although they demonstrated biochemical and histologic improvement. We have not assessed the reason for this phenomenon, but suspect that it results from the anorexia (secondary to flu-like symptoms) analogous to that occasionally observed in humans treated with rIFN (15).

Our studies provide evidence that M-CSF and rIFN, whether administered independently or in combination, are capable of increasing bone resorption relative to bone formation in an osteopetrotic mutant. The $\mathrm{mi} / \mathrm{mi}$ mutant does not have reduced numbers of osteoclasts or evidence of an M-CSF deficiency. MCSF was demonstrated to increase the therapeutic effects of rIFN administration. The increase in cellularity of the marrow spaces also suggests that the cytokines, whether administered independently or in combination, improve the hematopoiesis of the osteopetrotic animals, reducing the severity of the leukoerythroblastic anemia.

Interferon- $\gamma$ has been shown to reduce the number of osteoclasts (16) and the level of calvarial bone resorption (17) in tissues harvested from normal animals. However, in the present study, it appears that osteoclastic bone resorption was improved. Improved osteoclastic activity alone cannot be proven to have caused all of the change in bone marrow space noted. Because we did not specifically measure bone formation, it is possible that osteoblastic activity was inhibited. Nonetheless, the primary defect in the microphthalmic mouse is in osteoclastic function. Thus, an improved balance between bone formation and resorption implies an increase in osteoclastic function.

Superoxide generation appears to be an important element in achieving a normal level of osteoclastic function $(3,18)$. Microphthalmic mice that received both M-CSF and rIFN demonstrated the most significant improvement in cellular composition of the marrow space and augmentation of superoxide production, compared with sham animals. Hence, the combination of the two cytokines may result in an even more rapid improvement in the osteopetrotic condition than either cytokine administered separately. Although they did not elucidate the precise biochemical defect in osteopetrosis, the present studies suggest that rIFN and/or M-CSF administered to $\mathrm{mi} / \mathrm{mi}$ mice stimulates bone resoprtion, hematopoiesis, and immune competence, and thereby ameliorates the osteopetrotic condition.

Acknowledgments. The authors thank Genentech and Genetics Institute for their gifts of rIFN and M-CSF, and Dr. Robert Jilka for his assistance in acquiring and establishing the microphthalmic mouse colony. We also thank William C. Wolf and Heather Hatcher for their technical assistance in performing the histology and Bonita Pitzer and Dr. Arthur Shepard for performing the pilot experiments. We thank the Comparative Medicine departments of the Medical University of South Carolina and the Bowman Gray School of Medicine, Wake Forest University for their dedicated assistance in the care and welfare of the mi/ mi colony. 


\section{REFERENCES}

1. Key LL 1987 Osteopetrosis: a genetic window into osteoclast function. In: Zackson DA (ed) CPC Series: Cases in Metabolic Bone Disease. Triclinica Communications, New York, pp 1-12

2. Beard CJ. Key L. Newburger PE. Ezekowitz AB, Arceci R, Miller B, Proto P. Ryan T. Anast C. Simons ER 1986 Neutrophil defect associated with malignant infantile osteopetrosis. J Lab Clin Med 108:498-505

3. Key LL. Ries WL. Taylor RG. Hays BD. Pitzer BL 1990 Oxygen derived free radicals in osteoclasts: the specificity and location of the nitroblue tetrazolium reaction. Bone 11:115-119

4. Wiktor-Jedrzejczak W. Ahmed A. Szczylik C. Skelly PR 1982 Hematological characterization of congenital osteopetrosis in op/op mouse. Possible mechanism for abnormal macrophage differentiation. J Exp Med 156:1516-1527

5. Felix R. Cecchini MG. Hofstetter W. Elford PR. Stutzer A. Fleisch H 1990 Impairment of macrophage colony-stimulating factor production and lack of resident bone marrow macrophages in the op/op mouse. J Bone Miner Res 5:781-789

6. Garrett IR, Boyce BF, Oreffo ROC. Bonewald L. Poser P. Mundy GR 1990 Oxygen-derived free radicals stimulate osteoclastic bone resorption in rodent bone in vitro and in vivo. J Clin Invest 85:632-639

7. Ezekowitz RA. Dinauer MC. Jaffe HS, Orkin SH. Newberger PE 1988 Partial correction of the phagocyte defect in patients with $\mathrm{x}$-linked chronic granulomatous disease by subcutaneous interferon gamma. $N$ Engl $\mathrm{J}$ Med $319 \cdot 146-151$

8. Marks SC 1984 Congenital osteopetrotic mutations as probes of the origin. structure and function of osteoclasts. Clin Orthop Rel Res 189:239-263

9. Felix R. Cecchinı MG. Heisch H 1990 Miacrophage coluny stimitulating factor restores in vivo bone resorption in the $o p / o p$ osteopetrotic mouse. Endocrinology 127:2595-2594

10. Kodama H. Yamasaki A. Nose M. Niida S, Ohgame Y. Abe M. Kumegawa M. Suda T 1991 Congenital osteoclast deficiency in osteopetrotic (op/op) mice is cured by injections of macrophage colony-stimulating factor. J Exp Med 173:269-272

11. Hattersley G. Owens J. Flanagan AM. Chambers TM 1991 Macrophage colony stimulating factor (M-CSF) is essential for osteoclast formation in vitro. Biochem Biophys Res Commun 177:525-531

12. Orchard PH. Dahl N. Aukerman SL. Blazar BR, Key LL 1992 Circulating macrophage colony stimulating factor is not reduced in malignant osteopetrosis. Exp Hematol 20:103-105

13. Loutit JF, Sansom JM 1976 Osteopetrosis of microphthalmic mice: a defect of the hematopoietic stem cell? Calcif Tissue Res 20:251-259

14. Marshall MJ, Nisbet NW, Stockdale M 1983 Osteopetrosis in the Gruneburg (mi) mouse can be cured by cultured allogenic bone marrow. Cal Tissue Int 35:812-814

15. Kurzrock R. Quesada JR. Talpaz M. Hersh EM. Reuben JM. Sherwin SA Gutterman JR 1986 A phase I study of multiple dose intramuscularly administered recombinant gamma interferon. J Clin Oncol 4:1101-1109

16. Takahashi N. Mundy GR. Roodman GD 1986 Recombinant human interferon gamma inhibits formation of human osteoclast-like cells. J Immunol $137: 3544-3549$

17. Gowen M. Mundy GR 1986 Actions of recombinant interleukin 1, interleukin 2. and interferon-gamma on bone resorption in vitro. J Immunol 136:2478 2482

18. Ries WL. Key LL. Rodriguiz RM 1992 Nitroblue tetrazolium reduction and bone resorption by osteoclasts in vitro inhibited by a manganese-based superoxide dismutase mimic. J Bone Miner Res 7:931-939 